\title{
An overview of the spiritual importances of end-of-life care among the five major faiths of the United Kingdom
}

\author{
Authors: Mohsin Choudry, ${ }^{A}$ Aishah Latif ${ }^{\mathrm{B}}$ and Katharine G Warburton ${ }^{\mathrm{C}}$
}

For many who pertain to particular theological paradigms, their faith cannot be compartmentalised, but is mobilised to inform all aspects of their being, most notably their ethical and moral persuasions. As clinicians, the concept that there are good and bad deaths is already known; understanding the origin and depth of non-physical suffering, and aiming to alleviate it is not possible without learning the individual experiences and beliefs that go with it. Spiritual care forms a fundamental consideration in the endeavor to address the holistic experience of those patients receiving palliative care. Good palliative care seeks to promote the wellbeing and priorities of those with faltering health in a way that continues to support individualised notions of self-determination. The last few decades have resulted in a multicultural and multi-ethnic patient population. Addressing the spiritual and physical needs of patients allows healthcare professionals to deliver truly holistic care. Exploring and understanding the specific nuances of the five major religions of the UK provides healthcare professionals the opportunity to comfort the religiously observant patient at the end of life.

\section{Introduction}

Healthcare has traditionally focused on the physical aspects of care, while often overlooking the spiritual and psycho-social needs of patients particularly at the end of life. ${ }^{1}$ The end of life is often where spiritual matters come to the fore and patients may wish to re-examine and reiterate their beliefs in order to die peacefully. Most religions involve submission to a divine entity, and provide guidance on how to live purposefully, as well as rituals which comfort and influence patients and their families at the end of life. ${ }^{1,2}$ Discussions about spirituality may induce anxiety in healthcare professionals as they may not be accustomed to leading such conversations due to a lack of knowledge or cultural understanding. ${ }^{1}$ Exploring the main faiths of the UK allows healthcare professionals to pause and reflect on delivering effective and culturally competent care. This paper seeks to

Authors: Anational medical director's clinical fellow, Royal College of Physicians, London. UK; ${ }^{\text {B }}$ Clinical fellow in intensive care, Royal Free Hospital, London, UK; ${ }^{C}$ specialist trainee in acute medicine, North West London Deanery, Chelsea and Westminster NHS Foundation Trust, London, UK examine some of the issues that healthcare professionals may encounter when caring for patients from the five major faith groups of the UK: Christianity, Islam, Hinduism, Sikhism and Judaism.

\section{Background}

The UK is no longer a homogenous religious and cultural entity. An increasingly diverse population has emerged in areas such as London, Birmingham, Manchester, Leeds and Glasgow. Providing culturally competent end-of-life care presents a challenge for medical practitioners, particularly in areas with high concentrations of ethnic or religious minority groups. ${ }^{2}$ According to the 2011 census for England and Wales, the five largest religions are Christianity (33.2 million followers, 59.3\%), Islam (2.7 million followers, $4.4 \%)$, Hinduism (817,000 followers, $1.5 \%)$, Sikhism (420,000 followers, $0.8 \%$ ) and Judaism (263,000 followers, $0.5 \%)^{3}$

Palliation and end-of-life care has become increasingly medicalised and continues to receive attention among the media, healthcare professionals, ethicists and politicians. ${ }^{4}$ Historically, people died at home within the comfort of the surroundings of their community, where their own religious beliefs and traditions were conducted with ease. A significant number (47\%) of the 500,000 deaths in the UK occur in hospitals. ${ }^{5}$ The UK government has made a firm commitment to patients approaching end of life, stating that all should have access to personalised care which focuses on the preferences, beliefs and spiritual needs of the individual. ${ }^{4}$ Furthermore, physicians and their teams should utilise a framework of assessing palliative care needs, as established in the 2015 National Institute for Health and Care Excellence (NICE) guidelines, which incorporates religious and spiritual needs alongside physical, psychological and social considerations. ${ }^{6}$

Sociocultural beliefs at odds with current and conventional westernised medical practice can easily lead to conflict between healthcare professionals, patients and their loved ones. For example, conflict may arise in relation to the religious sanctity of life versus the medical opinion of 'futility'. 7 This requires healthcare professionals to develop an understanding of the sociocultural and religious traditions observed by the community served. Such an understanding may enhance the patient's endof-life experience and avoid conflict. ${ }^{1,8}$ This allows patients to selfdetermine by recognising their own idiosyncratic priorities through reconnecting to their source of empowerment - their own religious and cultural platform. The family is frequently the patient's advocate and voice, and as the patient is dying, the family also 
requires care. With the increased emphasis on providing holistic and person-centred care, healthcare professionals should strive to begin a dialogue to ensure the spiritual needs of patients and their families are addressed. ${ }^{1}$

To all of these religions the end-of-life experience is important, and represents the passing from the physical world to beyond. The endeavour to provide a peaceful death is one that is ubiquitously important to all religious communities. Most religions uphold the belief that life is sacred, and there is therefore an assumption that the preferences and beliefs of those with faith would be for prolonging life where possible; however, this is not always the case.

This article is written with the understanding that there is a large degree of variation among religious and cultural practices from modest observance to puritanical orthodoxy, particularly among the three Abrahamic faiths. Therefore, while recognising these variations, we have chosen to limit our discussion to the mainstream doctrines from each faith. Our intention is in no way to constrict other traditions but to recognise the limitations of the scope and breadth of this paper. In addition to this, this paper seeks to provide a general overview and is in no way meant to be a detailed analysis of the spiritual importance's to each of the five major faiths of the UK.

\section{Christianity}

\section{Ars Moriendi}

Christianity is a monotheistic religion based on the life, teachings and miracles of Jesus Christ. With the development of the Christian faith and doctrine over the course of two millennia, there is a vast body of published literature on faith, tradition and ritual at the end of life. Six centuries ago, the Roman Catholic Church published the most popular of these, the Ars Moriendi or 'The art of dying well'. With the attainment of eternal life with God at the heart of most Christian beliefs, the acknowledged relationship between death and religion is not surprising. Published in the 1400 s, the Ars Moriendi served as a guide for Christian families to plan and create a good death. It warned against the temptations of lack of faith, despair, impatience, vanity and greed. ${ }^{9.10}$ Admittedly, there have been enormous advances in medicine and understanding since the Ars Moriendi was published; indeed, regarding terminal delirium as 'impatience' would show a sad want of compassion and competence today. However, the presence and popularity of the book and, indeed the launch of the contemporary The art of dying well by the Catholic Church of England and Wales in $2016^{11}$ demonstrates its relevance today and that terminal suffering cannot be wholly relieved by pharmaceuticals, and that there is an overwhelming need for good spiritual care at the end of life.

\section{Christianity in the UK}

Christianity is the world's largest religion, with 2.2 billion followers (32\% of the world's population). ${ }^{12}$ It is globally the most evenly spread religion with $50 \%$ describing themselves as Roman Catholic, $37 \%$ as Protestant and $12 \%$ Orthodox Communion (Russian and Greek) and 1\% 'Other' (Christian Scientists, Mormons and Jehovah's Witnesses). ${ }^{12}$ Christianity remains the predominant religion within the UK. ${ }^{3}$ The UK has a larger proportion of Protestants, with $54 \%$ describing themselves as Protestant and $17 \%$ as Roman Catholic. ${ }^{13}$ Largely, the focus of this paper will be on Protestantism, predominantly Anglicanism (as here again there are many differing churches) and Catholicism as the two leading Christian denominations in the UK.

Given that medical practice within the UK has evolved in a predominantly Christian country, it is not surprising that current medical and legal practice around dying is accepted and allied in conjunction with Christian beliefs. The information set out here is an attempt to harness and sketch the broad outline of significant beliefs around dying that many mainstream Christians will hold and therefore should be a point of reference for discerning what holistic end-of-life care might mean for them.

\section{Christian beliefs about death}

Christians believe in the resurrection of the dead: the future embodied existence of human persons which has been determined by Christ's resurrection. The vast majority of Christians believe that at the return of Christ, God will administer 'Divine judgement', with mercy and justice, leading to either eternal salvation or damnation.

I am the resurrection and the life. Those who believe in me, even though they die, will live, and everyone who lives and believes in me will never die.

Holy Bible, New Revised Standard Version - John 11:25-26

Central to most Christian beliefs is that God reveals himself as the Father, the Son and the Holy Spirit (the Trinity). Christians believe that Jesus Christ suffered and died in humanity's place, making available forgiveness for sins and breaking sin's power to enslave people; with his resurrection he conquered death, opening up an everlasting life in communion with God and God's people.

Death has been swallowed up in victory. Where, $O$ death, is your victory? Where, $O$ death, is your sting?

Holy Bible, New Revised Standard Version - I Corinthians 15:54-55

Christian understanding around the end of life pivots around two central points: namely, upholding the sanctity of life, because God has given it; and being fearless of death because of the hope of communion with God..$^{14}$ Christians believe that they were made in God's image and that God honours, respects and loves them. They believe in one journey through earthly life which ends in death. By God's grace this may be a life that is lived by faith and through repentance in accord with God and God's promise of resurrection after death in certain hope of heaven. Christians believe human life is precious and holy; this leads some to reject any shortening of life by anyone except God. 14,15

Many Christians believe that Jesus' death by crucifixion is a model of a good death, whereby he showed an acceptance to die, combined with compassion and forgiveness for those who wronged him, and a firm belief in bodily resurrection leading to an eternal communion with God. ${ }^{16}$ For this reason, peace, assurance of the forgiveness of sins and confidence in the fellowship of the Holy Spirit and God's people are the focus of Christians' journey towards the end of life.

\section{Practical approach to caring for Christian patients nearing the end of life}

Both Roman Catholics and Protestants who are dying may wish to be visited by a person from their church. Patients belonging to 
the Church of England may value prayers at the bedside, being anointed and/or taking Holy Communion. In addition to prayers and Holy Communion, Roman Catholic patients may desire the Sacrament of the Sick with anointing, which can only be performed by a priest and is commonly described as 'Last rites'.

Christians believe that life is a sacred gift from God and as such do not allow assisted suicide or euthanasia. ${ }^{14-16}$ However, Christians do not believe that life should be prolonged at all costs: ${ }^{15}$ they accept the use of analgesia and sedation to relieve terminal suffering provided it does not consciously take away a person's life or opportunity for repentance.

After death, all Christians expect their bodies to be treated with respect. Many Christians are taught that organ donation is an act of love and a way of following Jesus' example, so there is no strong Christian objection to organ donation and is mostly actively encouraged. ${ }^{17}$ However, some Christian individuals, may have personal reservations; for example, many will insist that brainstem death is not the death of the person and so donation should only take place after cardio respiratory functions have ceased. ${ }^{18}$ In general terms, Christians believe that nothing can happen to their body before or after death that will affect their relationship with God, and as such have no religious objection to post-mortem. ${ }^{19}$ Bodies may be buried or cremated at a time determined by the family; there is no timescale dictated by religion within which the funeral must be held. At the time of cremation or burial, a priest will typically say words such as:

We have entrusted [name] to God's mercy, and we now commit his/her body to the ground: earth to earth, ashes to ashes, dust to dust; in sure and certain hope of the Resurrection to eternal life, through our Lord Jesus Christ

Common Worship 2000-2008, (Church of England)

Key points on Christianity and end of life are summarised in Box 1.

\section{Box 1. Key points: Christianity and the end of life}

Christians believe in the resurrection of the dead and everlasting communion with God and that a good death is part of this process

Clinicians should recognise that the cluster of traditions and denominations making up the Christian faith have some theologically grounded variations that may influence end-oflife decisions

Christians believe that life is a sacred gift from God and as such do not allow assisted suicide or euthanasia

Both Roman Catholics and Protestants who are dying may wish to be visited by a person from their church. Roman Catholics may wish to receive the Sacrament of the Sick with anointing (Last rites)

Christians recognise the medical benefits of organ donation (although for many, this should only follow full cardiorespiratory death not merely brainstem death) and do not regard their beliefs as being in opposition to post-mortem

Funerals themselves vary between the different churches and traditions; they typically involve readings from scripture, hymns and eulogies. They are, religiously speaking, celebrations of a person's life, with thankfulness for the person's faith and membership of God's family

\section{Islam}

Linguistically, Islam means to surrender oneself. On a tangible level, this surrender is one in which the individual independently seeks to internalise and reproduce the qualities that make God deserving of gratitude. ${ }^{20}$ The higher moral objectives that Muslims are encouraged to uphold aim to serve the physical and spiritual welfare of human beings and show no contention with the four main principles of secular medical ethics. Individual autonomy is understood as contingent upon overarching autonomy/ sovereignty, which Muslims believe resides ultimately with God and is shared with human beings in order for them to self-determine. Muslims are encouraged to uphold justice at all costs:

You who believe, uphold justice and bear witness to God, even if it is against yourselves, your parents or your close relatives.

Al-Quran 4:135 (Translation by M.A.S Abdel Haleem, Oxford University Press 2004)

When considering 'Islamic law' it is important to give due respect to the Islamic scholastic tradition, which remains incredibly pluralistic and diverse. The Muslim body is not monolithic and there exists an accepted understanding of multiple equally legitimate schools of thought that attempt to explore the divine will while maintaining that no single jurist or institution possesses undivided or sole representation. ${ }^{21}$ Respect for, and upholding, the intellect and dignity of human beings is considered one of the higher objectives of the Shariah. This is not to be confused with the jurisprudential process by which principles of Shariah are actualised, known as 'fiqh'. Shariah is therefore considered the immutable and timeless law as understood within the realm of the divine, whereas 'Islamic law' or 'fiqh' is the imperfect process by which human beings attempt to recognise the way of God.

The topics addressed below, seek to outline some of the orthodox opinions with respect to varying denominations within end-of-life care for the Muslim patient. It would be naive to assume that this could potentially cover all spiritual considerations for an incredibly varied and diverse body of people.

\section{Dying and resuscitation}

The role of 'Do not attempt resuscitation' (DNAR) orders is to anticipate those patients for whom cardiopulmonary resuscitation (CPR) would be a futile intervention and to allow the natural process of death to ensue comfortably. The implementation of DNARs can often be regarded as congruous with respect for human dignity and is 'equivalent to comfort care, 22 , as viewed by many Muslim physicians. There also exists among the Muslim community the recognition of brainstem death as a concept where consciousness is lost and the patient no longer has the ability to breathe for themselves, under which certification of death can be delivered. ${ }^{23}$ The above has been legalised in Islamic jurisprudence, secondary to the Third International Conference of Islamic Jurists (1986). ${ }^{23}$ It is perceived that when death is inevitable the patient should be allowed to die without unnecessary procedures; for example, if the patient is on mechanical life support, this can be withdrawn., 24

\section{Artificial nutrition and hydration}

It is fairly ubiquitously recognised that the role of artificial nutrition and hydration should be one of comfort and sustenance for the 
patient in the appropriate context. Where artificial nutrition and hydration no longer provides comfort or its risks prove greater than its benefits, such intervention can be legitimately withdrawn. ${ }^{24}$ There exists in Islam the concept of attaining meaning through suffering. It is important to note the delicate balance between recognising the inevitability of death and its related tribulations while continuously recognising the importance of reducing individual suffering and promoting physical and spiritual wellbeing. $^{25}$

\section{Organ donation}

There exist varying opinions on the procedure of organ donation within the Muslim community. ${ }^{26}$ Many argue of the benefits and beauty of organ donation through its ability to deliver enhanced human functionality and preservation of life, in keeping with higher objectives of Shariah. The above exists as a predominant opinion among Muslims residing within the middle east. However, others are dubious with respect to the perceived desecration of the human body, which is regarded as sacred. For example, there exists opposing sentiments within the Indian subcontinent regarding organ donation as controversial to preserving the sanctity of the human body. ${ }^{27}$

\section{Euthanasia}

Euthanasia and assisted suicide are prohibited in Islam, which recognises God alone as possessing the right to end life and regards life as sacred. ${ }^{28}$ The ability to exercise personal autonomy in this respect can be regarded as a 'category mistake' wherein life belongs to God who possesses ultimate sovereignty over the human being. ${ }^{29}$ Leading on from this, Shariah aims to not only protect the rights of the individual but also to address the holistic needs of the community; therefore, an argument to safeguard against the 'misapplication' of euthanasia or physician-assisted suicide is also valid. ${ }^{29}$ The sanctity of life in Islam is rooted in the concept of the soul which is from God and belongs to God alone. This by no way subverts the notion of withholding or withdrawing treatment where such acts would be futile or cause more harm than good in the context of the natural dying process. Islam advocates the endeavor to ease suffering at all costs while maintaining that patience and forbearance through tribulations are virtuous qualities in a world where strife is inevitable.

\section{Ritual ablutions and timely funeral prep}

The majority of Muslims will wish to proceed with a timely burial of their loved ones on the pronouncement of death. It is important for healthcare professionals to consider the universalism of spirituality that Islam propagates and the numerous ways this influences the patient experience, especially in the context of endof-life care.

It is necessary for doctors to appreciate the need for prompt certification of death in order to facilitate funeral and after death preparations. Cremation is not recognised as an orthodox Islamic practice and Muslims are usually buried. Following death, Muslims tend to wrap the deceased in a white cloth or shroud following ritual ablutions. ${ }^{30}$ Muslims aim to undertake the burial of the deceased as soon as possible and the community is encouraged to attend the funeral to offer prayers and engage in spiritual reflection. ${ }^{31}$

Key points on Islam and end of life are summarised in Box 2.

\section{Box 2. Key points: Islam and the end of life}

Muslims pray only when ritually clean, and are not able to pray among bodily fluids or waste

Muslims will often wish to bury their dead as soon as possible. Therefore, timely release of the death certificate is vital

The Shariah does not recognise suicide; the right to die is not voluntary and it is forbidden to terminate life prematurely either actively or passively

Islam is not a monolithic religion or set of beliefs and due to a sociocultural variations, some patients will choose to defer to their own scholarly views

\section{Judaism}

Judaism is a religion based on an ancient law of God, the 'Halacha', the foundations for which are the 613 Mitzvot (commandments) and Torah. ${ }^{32}$ Jews have a rich tradition and culture, and this is reflected in their approach to end-of-life care. Judaism recognises the infinite value of life and believes that death is God's will. Observant Jews make decisions about their lives and health based on the Halacha, often with the help of their rabbi. Observant Jews can be Orthodox, Conservative or Reform and practices may vary. Orthodox Jews consider the Halacha as non-negotiable and therefore will continue to remain observant at the end of life; this can include observing Shabbat (Sabbath) and a strict Kosher diet. ${ }^{2}$ The following is written from an Orthodox perspective.

Physicians caring for the Orthodox Jewish patient can expect to encounter deeply held beliefs, a complex code of religious observance, and a delicate balance between patient autonomy and rabbinic authority. ${ }^{8,33}$ Life is sacred to Jews and the obligation to save a life - 'Pikuach nefesh' - is of the greatest importance and surpasses virtually all other duties. ${ }^{7}$ Healing is considered a Mitzvah (commandment); however, there are certain circumstances where this is not applicable, eg when a patient who is terminally ill must undergo treatments which are severely painful, do not prolong life, or prolong severe suffering. ${ }^{7}$

Jewish medical ethics, derived from the Halacha, incorporates the four cardinal secular principles of autonomy, beneficence, non-maleficence and justice. In Judaism, autonomy is shared with rabbinical governance. ${ }^{32}$ Orthodox Jews voluntarily limit their autonomy, with the assistance of their rabbis, to make decisions that are consistent with the Halacha. ${ }^{32}$ Both physicians and rabbis are viewed as partners in making decisions about treatment. ${ }^{34,35}$ The principle behind this is that the Halacha does not recognise the proprietary right to one's body or life, it is God given, and therefore the preservation of health and seeking preventative and curative medical care are of the utmost importance. $7,32,34$

\section{Terminal illness}

In approaching terminal illness, there are two recognised phases 'Chayei sha'a/Treifah' and 'Goses'. Chayei sha'a/Treifah refers to a terminal patient where death is likely in the near future; while not absolute this is often viewed as less than a year of life., 7,32,35 Goses refers to an agonal patient whose time has come; while not concrete, this is usually recognised as a person with less than 72 hours to live. ${ }^{7,32}$ The Halacha views these two categories of 
patients differently. ${ }^{7}$ In the case of the Chayei sha'a there are distinctions to be made in relation to withholding and withdrawing treatment that are beyond the scope of this paper.

The Halacha forbids actions that would hasten or impede death in a Goses. ${ }^{8}$ Jews believe the Goses may not be moved as their hold onto life is so fragile that even the slightest movement can hasten death, ${ }^{32}$ which may be viewed as akin to taking their life. ${ }^{7}$ Medical treatment that merely prolongs the state of the Goses may be withheld; however, Goses are considered alive in all respects and if a treatment suddenly becomes available that would reverse the status of Goses then it must be administered. ${ }^{7}$ If, however, the life of a Goses can be prolonged for only a short period, at a cost of great suffering, then there is no obligation to do so. ${ }^{7}$ In modern medicine the recognition of the Goses can be difficult since suctioning and medications can clear the terminal secretions that traditionally identify the agonal patient; clarity may be provided with the assistance of a rabbi. ${ }^{32}$ In determining the resuscitation status of a patient should they suffer cardiorespiratory arrest it is accepted that CPR may be withheld from, or refused by, the terminally ill. ${ }^{32}$

\section{Analgesia}

Administration of analgesia is a delicate balance in the Goses, and some rabbinical authorities have concerns regarding respiratory depression. ${ }^{35}$ However, while Judaism is fully supportive of the appropriate treatment of pain, it must never be used with the intention of hastening death. ${ }^{7,32}$ Where concerns are highlighted it is important to ensure that the patient/family and rabbi are aware that evidence suggests that appropriate pain relief does not usually shorten the life of terminally ill patients. ${ }^{8,36}$

\section{Nutrition}

Virtually all Orthodox rabbinical authorities consider oral and intravenous fluids, nutrition and oxygenation as essential components of life and not treatment; therefore, they require provision. ${ }^{7,8}$ While it is recognised that oral feeding can be dangerous, it is viewed that other methods should be utilised in complex patients. ${ }^{7}$ The insertion of a feeding tube is considered indispensable in providing nutrition to the dying patient; however, this is not without risk and may be contraindicated. ${ }^{8}$ A more balanced approach may be that while Jewish patients who are terminally ill should be provided with nutrition, those delivering their care also have a duty to ensure that the method of delivery does not cause further harm. It is important to realise that this forms part of satisfying the caregivers obligation to provide the patient nourishment. ${ }^{8}$ Furthermore, it is viewed that death will certainly ensue if food, oxygenation and fluids are withheld for long enough, which is forbidden in the Halacha. ${ }^{7}$ It is acceptable to withhold nutrition where a patient will clearly die from their underlying pathology sooner than a lack of nutrition. ${ }^{7,34}$

\section{Withdrawal and withholding treatment}

Withdrawal of directly life-prolonging interventions is not permissible; however, in recognising that such interventions may only be serving to impede the dying process there may be some exceptions. ${ }^{32}$ When death is near, many rabbis take into consideration the increased suffering accompanying terminal illness when determining how much medical intervention should be employed to prolong life. ${ }^{8}$ It is permissible to withhold treatment when, in the view of the medical team, the treatment will not result in a cure or does not provide relief to suffering. ${ }^{32}$ For example, it is not deemed compulsory to place a terminally ill patient on life support ventilators. However, active withdrawal is against the Halacha, as withdrawal may hasten death. While recognising that it is forbidden to withdraw, some rabbinical authorities allow patients to be placed on a ventilator with an automatic clock, which after shutdown allows the team to reassess. If determined that there is no improvement in the patient's condition a consultation with the family/rabbi can lead to the decision whether or not to restart. However, this would require the foresight to place the patient on a timed ventilator. This is generally an area which depends largely on local customs and remains controversial. ${ }^{32,34}$

\section{Euthanasia and suicide}

The Halacha states a person's life is not theirs to give away and there is an obligation to avoid bodily harm;, 7,32 therefore, suicide is forbidden. Euthanasia is not an option. It is deemed the solution to unbearable suffering is to bring relief, not hasten death. ${ }^{7}$ Deliberate hastening of death in any patient, including the Goses, is seen as 'an act of murder' according to the Halacha. ${ }^{32}$ Decisions and actions by healthcare professionals that may directly or indirectly shorten life are therefore forbidden. ${ }^{8}$

\section{Defining death}

The UK, unlike the USA, does not have a legal definition of death; however, a similar criterion is followed. ${ }^{37}$ There are important distinctions and differences with regard to the western secular definition of death, particularly that of brainstem death in the ventilated patient. However, the sole criterion of death accepted by the Halacha is "complete and irreversible cardiopulmonary cessation', 7,38 Debate exists among rabbinic scholars in accepting the 1968 Harvard definition of brainstem death, ${ }^{38,39}$ as those who are declared brainstem dead may still exhibit signs of breathing and therefore it is not accepted as a definition of death. ${ }^{7}$ Some rabbinic authorities will accept the Harvard brainstem death definition ${ }^{7}$ but it is not the accepted view of the mainstream Orthodox community in the UK.

\section{Organ donation}

Organ donation is deemed acceptable in Judaism; however, due to discrepancies with the definition of brainstem death as an acceptable criterion to harvest organs, this would be unacceptable for many Orthodox Jews, who only accept cardiopulmonary death. A balance is required between the duty to preserve one's own life and the duty to serve and help others live. ${ }^{34}$ It is crucial that the medical team, family and rabbi agree on the process of organ donation. ${ }^{8}$

\section{After death}

After death the eyes are closed and covered with a white sheet and the body is placed face up with feet towards the door (some traditions). ${ }^{40}$ Some will observe a period of $20-30 \mathrm{~min}$, depending on local customs, where the body is not moved to ensure complete cessation of cardiopulmonary activity. ${ }^{7,38}$ Jewish law commands 
Box 3. Key points: Judaism and the end of life ${ }^{8,32-35,38,40}$

Jewish law is specific, and may appear inflexible; however, rabbinic interpretations and an improved understanding of modern medicine demonstrate that there is flexibility when approaching end-of-life care

Rabbinic involvement in medical decision making is common and may challenge conventional patient autonomy, particularly at the end of life where the threshold for withholding life sustaining treatments in view of 'futility' may be higher than western trained physicians. However, this is not universal and careful explanation of treatments and prognosis is vital in allowing the family to make decisions together with rabbis

> Patients may request medical interventions which the medical team may be uncomfortable with, as the Halacha requires a physician to do everything in their power to prolong life, but prohibits actions which prolong the act of dying or hasten death

Healthcare professionals should explore and establish the importance of prayer needs, Shabbat observance and the degree of involvement of the rabbi and family in decision making

Jews refrain from actions considered work on the Shabbat, such as writing, carrying, use of electrical devices or business transactions. Be mindful of this when treating patients observing Shabbat, for example when prescribing patientcontrolled analgesia (PCA)

$>$ A dying patient should not be left alone and Jews will wish to fulfil their obligation of 'Biqqur Cholim' (visiting the sick)

$>$ Judaism prohibits prayer in the presence of bodily fluids. The dying patient can be incontinent, so if the patient cannot be continually cleansed the family/clinical team should seek rabbinical guidance to determine the correct course of action

that the body is watched over and must not be left alone at any point until burial as a sign of respect. Local burial committees called the 'Chevra Kadisha' arrange this service and prepare the body for burial. ${ }^{8,35}$ The body is washed by members of the same sex, shrouded and placed in a simple coffin. The Halacha requires that the dead are buried within 24 hours; therefore, urgent death certification is often of great importance. ${ }^{8}$ The removal of the body may be delayed should death fall on Shabbat.

Key points on Judaism and end of life are summarised in Box 3.

\section{Hinduism}

Hinduism, practiced by billions worldwide, is one of the world's oldest religions. ${ }^{41}$ There is no founder, single point of origin or central text; however, most accept the teachings within the Bhagavad Gita. Hindus believe in one God, Brahman; however, there are many different manifestations, which explains why Hinduism has many different 'gods' representing characteristics of Brahman. ${ }^{42}$ Indeed, Hinduism could be described as more of a philosophy as it does not mandate adherence to a particular doctrine and as such issues relating to end-of-life care are not specifically addressed within its philosophy. ${ }^{41}$ Hinduism spans an entire subcontinent and as such has a diverse range of beliefs and practices. Most Hindus, however, adhere to the concepts of family, karma, reincarnation and community interconnectedness and as such life is viewed as being part of a continuum. 2,41-44.

\section{'A good death'}

Hindu's believe death should come at a natural and proper time. Of particular importance is the notion of a 'good death'. A 'good death' is timely, in the right place, conscious, and prepared with the mind on God. ${ }^{44} \mathrm{~A}$ 'good death' is signified by a long life and the opportunity to say goodbye and settle affairs on earth. Therefore, an elderly Hindu will often want to fulfil their duties and responsibilities and resolve conflicts. ${ }^{42}$ Before death, Hindus may wish to give offerings to needy or the temple. ${ }^{2}$ Families hope for a 'good death' and may look for a peaceful expression with the eyes and mouth slightly open to indicate the soul has departed. A 'bad death' is feared, and is signified by a death that occurs with an unpleasant expression, prematurely, or in an undesirable place or unclean circumstance, eg death among vomit, urine and faeces. ${ }^{44}$

\section{Karma}

Karma guides Hindus on how to live life. The law of karma is a moral one of cause and effect, and determines lifecycles and rebirth. Karma follows a hierarchy, based on the accumulation of spiritual merit of good and bad deeds throughout multiple lifetimes. ${ }^{42}$ This doctrine strongly influences a Hindu's attitude to life, particularly as they view all life events as the result of karma. ${ }^{43}$ In this regard, Hindus believe that 'suffering' is born as a result of past karma. ${ }^{44}$ Suffering and illness are not seen as unique to the individual, rather viewed as the result of prior actions in this, or a previous life. ${ }^{41}$ Such suffering may be caused by physical, emotional and spiritual pain. Some may wish to endure this pain and refuse analgesia to avoid reducing consciousness to focus their mind on God ${ }^{43}$ and as a method to 'release' sins. ${ }^{45}$

\section{Practices and beliefs}

Hindus believe life should not be prolonged unnecessarily by aggressive medical or mechanical interventions when it is clear that the prognosis is poor as this may interfere with the soul's karma in passing from this life to the next. ${ }^{41,42}$ Thus DNAR orders are widely accepted.

\section{Family}

Hinduism is intertwined with a family-orientated culture. There is a strong tradition of preparing for death, although the family may not always wish for the patient to know the specifics of their illness and prognosis. ${ }^{41,44}$ Patients, particularly the elderly, may wish for their family to make decisions on their behalf. ${ }^{43}$ Such decisions are often delegated to the eldest son or eldest male relative. ${ }^{41,42}$ This may present the healthcare professional with a dilemma on issues such as consent and shared decision making and needs to be navigated carefully.

\section{Euthanasia and suicide}

Suicide for 'selfish' reasons is seen as the 'worst' type of death and is deemed morally unacceptable. ${ }^{44}$ Involuntary euthanasia is 
not acceptable in Hinduism and would result in bad karma for the healthcare professional. ${ }^{44}$ However, a 'willed death' (Prayopavesa) in a spiritually advanced person is viewed differently, in addition to an individual enduring a great deal of suffering, who may wish to end their suffering using a 'self-willed' fast. ${ }^{42}$ An individual who seeks death consciously and willingly for the intention of liberation from suffering is viewed differently. ${ }^{46}$ However, while there is a tradition of voluntary suicide in the spiritually adept and in certain carefully defined circumstances, this is a controversial area and there is no formal consensus. ${ }^{44}$

\section{Last rites and death}

Performing last rites for some families are a must; it is perceived that interfering with this could impact on the karma of the family members. Such rites include turning the head east, applying holy water to the lips, and Tulsi leaf (Holy Basil) to the mouth while chanting into their right ear. ${ }^{41,42}$ Some families believe, regardless of consciousness, that hearing is the last sense active before death, and will be mindful of saying anything upsetting. ${ }^{2}$ Some elderly patients may wish to die on the floor, as is traditional amongst Brahmins, who perceive the bed as a barrier or intermediary between the earth and sky. ${ }^{44}$ Some may wish to light candles and recite religious texts, to assist the person to pass from this life to another. ${ }^{2}$ After death, with the exceptions of infants who are buried, due to their pure nature, adults are cremated. ${ }^{43,44}$

Key points on Hinduism and end of life are summarised in Box 4.

\section{Sikhism}

Sikhism, one of the world's youngest religions, was founded by Guru Nanak Dev Ji in the Punjab, India, as a reaction to the growing inequalities due to the hierarchy of the caste system. ${ }^{47,48}$ Sikhism's teachings were consolidated and expanded by the subsequent nine Gurus, ${ }^{49}$ culminating in the Granth Sahib, a holy text, which to Sikhs represents a 'living Guru'. Sikhism is a monotheistic religion and has several core values including equality, community service, striving to help others,

\section{Box 4. Key points: Hinduism and the end of life $e^{4 L}$}

Attempting to generalise in the Hindu patient is difficult. There is no single central authority or compliance with a single doctrine and so practices and traditions will vary greatly

There appears to be a universal belief in reincarnation and karma. Life on earth is viewed as a transition between the previous life and the next one

The family have a duty to assist the dying and to perform the last rites. Additionally, families may wish to protect their loved ones from the prognosis of death

Suicide is frowned upon but some traditions state grounds for voluntary euthanasia to prevent extreme suffering; however, this is a controversial and poorly defined area

Unnecessarily prolonging life when the prognosis is poor is viewed as interfering with karma and reincarnation

Non-faith members are permitted to handle the body provided they are of the same gender and remembering God. ${ }^{47}$ Similarly to Hindus, Sikhs believe in reincarnation ${ }^{50}$ and view their soul as eternal and therefore $e^{47,51}$ view death as the predetermined fate of the soul in the cycle of reincarnation. ${ }^{48}$

\section{The five Ks}

The five Ks are symbols of faith that must be maintained on the person. These consist of the 'Kara' (bangle), 'Kirpan' (a blunt ceremonial sword which may instead be worn in the form of a small pendant necklace), 'Kesh' (uncut hair), 'Kachh' (cotton underwear to protect sexual modesty), and Kangha (a comb worn in the hair). Sikhs believe hair is a gift from God, the cutting or removal of which is prohibited and should be avoided where possible unless urgent or life threatening. ${ }^{51}$

\section{Practices and beliefs}

The Sikh approach to healthcare is reflected in their approach to valuing science, living life, and seeking knowledge; therefore, almost all forms of treatment are permitted for a Sikh patient. When it is clear that Sikhs are approaching the end of life, this is viewed as the will of God, and predetermined fate and therefore Sikh's may forego difficult and risky treatments. Maintaining a terminal patient on artificial life support for a prolonged period of time is not encouraged if the prognosis is considered to be poor. ${ }^{48,51}$

Sikhs feel that the western ideal of individual autonomy is less applicable and instead place importance on a holistic approach to decision making, whereby the patient, family, and religion function as an integrated unit. ${ }^{48}$ Similarly to Hindus, Sikhs often designate a spokesperson, usually the eldest son, to speak on issues of consent and decision making. ${ }^{48,51}$ It is often felt that informing the family of terminal illness allows loved ones to deflect the impact of the diagnosis and prognosis from the patient. Many families may wish to protect the patient from the reality of their diagnosis and prognosis due to the fear that it may hasten death. ${ }^{48}$

\section{Death and dying}

As the final days approach family, community members, and a Granthi (priest) may recite from the Granth Sahib. ${ }^{51}$ Recitation of prayers and sacred shabads (hymns) is important as it allows the dying one to focus their mind on God and disengage from worldly and material matters, Sikhs believe if this state of mind is not reached then the soul will not be re-born. ${ }^{2}$

Suicide is forbidden, as the timing of death is in God's hands alone. ${ }^{51}$ There is no place for euthanasia in Sikhism and healthcare professionals do not have the right to end life; if no cure is available, destruction is not the solution. ${ }^{52}$ Organ transplantation, both donating and receiving, is permissible. ${ }^{51}$ This is emphasised by Sikh philosophy of altruism. ${ }^{48}$

At the time of death those gathered may recite 'Waheguru' (Wonderful Lord). The eyes are closed, limbs straightened, the family will want to arrange release of the body in order to ensure the five Ks remain intact, wash and shroud. ${ }^{49,51}$ Sikh's believe that the soul is the person's essence and the body is merely the vessel that housed it; ${ }^{47}$ therefore, prompt release of the body for cremation is the usual practice after death. ${ }^{2}$

Key points on Sikhism and end of life are summarised in Box 5. 
Box 5. Key points: Sikhism and the end of life ${ }^{52}$

Sikh beliefs towards end-of-life care are under-evaluated in the medical literature and further studies are required to explore attitudes and mainstream opinion

Sikhs have a strong tradition of accepting death, and believe in karma and reincarnation

The five K's are of fundamental importance to Sikhs and are to be respected and not removed unless life threatening. Observance of these symbols may become particularly apparent at the end of life

Many Sikhs will forego unnecessary and invasive lifeprolonging treatments when it is clear that it is futile

Sikhism is a social religion; therefore, a large number of community members may will wish to visit and offer support

\section{Conclusion}

This paper has sought to explore the differences and similarities of the five major faiths of UK, and demonstrates a richness of end-oflife rituals and practices, many of which enhance and complement the secular approach to current standards in palliative care. The five faiths strive for a peaceful end-of-life experience, and all discourage acts which hasten death, and share a largely unanimous opinion on euthanasia. There is, however, a wide heterogeneity among communities; therefore, it is important to recognise each individual may follow a paradigm based not only on religion but also ethnicity and culture.

While the modern approach to death is highly medicalised, we are reminded that it is also a social experience defined by rituals, beliefs and traditions. Therefore, caring for the religiously observant patient is complex and requires due consideration and accommodation of religious obligations and needs. The involvement of family, community and religious leaders is of particular importance to some as it enables the provision of meaning, spiritual renewal and comfort at the end of life.

Knowledge of the unique characteristics, nuances and traditions of the five major faiths will serve to significantly enhance the end-of-life experience for the patient, family and their religious community. Exploring and supporting patients through their religious beliefs can be as important as other physical clinical interventions. In order to ensure that competent sociocultural, sensitive and congruent care is delivered at the end of life a greater understanding and awareness is required within the healthcare profession.

\section{Acknowledgements}

We are grateful to Dr Miriam Fine-Goulden, consultant paediatric intensivist, for her comments on the Judaism section, and to Dr Joshua Hordern, associate professor of Christian ethics at the University of Oxford, for his comments on the Christianity section.

\section{References}

1 Morgenweck CJ. End-of-Life Issues: Spirituality. In: Jericho B. (eds), Ethical Issues in Anesthesiology and Surgery. Springer, Cham 2015 Available online at https://link.springer.com/book/10.1007/978-3319-15949-2\#about [Accessed 10 September 2017]
2 Public Health England. Faith at the End-of-life. London: Department of Health, 2016. Available online at www.gov.uk/government/ uploads/system/uploads/attachment_data/file/496231/Faith_at_ end_of_life_-_a_resource.pdf [Accessed 10 September 2017].

3 Office for National Statistics. Census 2011: Religion Statistics. www.ons.gov.uk/peoplepopulationandcommunity/culturalidentity/ religion/articles/religioninenglandandwales2011/2012-12-11 [Accessed 2 August 2017]

4 Department of Health. Our Commitment to you for end of life care. The Government Response to the Review of Choice in End of Life Care. London: Department of Health; 2016. Available online at www.gov.uk/government/uploads/system/uploads/attachment_ data/file/536326/choice-response.pdf [Accessed 25 October 2017].

5 National End of Life Care Intelligence Network. End of life care data profiles. London: Public Health England; 2017. Available online at www.endoflifecare-intelligence.org.uk/data_sources/ place_of_death [Accessed 28 December 2017].

6 National Institute for Health and Care Excellence. Care of dying adults in the last days of life. NICE guideline (CG31) 2015. Available online www.nice.org.uk/guidance/ng31?u nlid $=63448395420161011192124$. [Accessed 28 December 2017].

7 Tatz A. Dangerous Disease \& Dangerous Therapy In Jewish Medical Ethics Principles and Practice. 1st edn. Jerusalem: Targum Press, 2010.

8 Loike J, Gillick M, Mayer S et al. The critical role of religion: caring for the dying patient from an Orthodox Jewish perspective. J Palliat Med 2010;13:1267-71.

9 Thornton K, Phillips CB. Performing the good death: the medieval Arsmoriendi and contemporary doctors. Med Human 2009;35:94-9.

10 Leget C. Retrieving the ars moriendi tradition. Med, Health Care Philos 2007:10:313-9.

11 The Catholic Church of England and Wales. The Art of Dying Well. Available online www.artofdyingwell.org/ [Accessed 3 January 2018].

12 Pew Research Centre: The Global Religious Landscape, 2012. Available online at www.pewforum.org/2012/12/18/global-religious-landscape-exec/ [Accessed 19 October 2017].

13 Pew Research Centre. Five Centuries After Reformation, CatholicProtestant Divide in Western Europe Has Faded, 2017. Available online at www.pewforum.org/2017/08/31/five-centuries-afterreformation-catholic-protestant-divide-in-western-europe-hasfaded/ [Accessed 19th October 2017].

14 Engelhardt HT, Iltis AS. End-of-life: a Traditional Christian view. Lancet 2005;366:1045-9.

15 Markwell H. End-of-life: a Catholic view. Lancet 2005;366:1132-5.

16 Vogt CP. Practicing patience, compassion, and hope at the end-oflife: mining the passion of Jesus in Luke for a Christian model of dying well. J Soc Christian Ethics 2004;24:135-58.

17 Church of England. General Synod backs call to encourage blood and organ donation. Church of England Media Centre 2016. Available Online https://www.churchofengland.org/more/mediacentre. [Accessed 3 January 2018]

18 Hordern J. Religion and Culture. Medicine 2016;44:589-92.

19 Connolly AJ, Finkbeiner WE, Ursell PC, Davis RL. Autopsy Pathology: A Manual and Atlas. 3rd edn. Philadeliphia: Elsevier Inc, 2016.

20 Abou El-Fadl KM. The Great Theft 1st edn. New York: HarperCollins, 2007.

21 Abou El-Fadl KM. Reasoning with God: Reclaiming Shari' ah in the Modern Age 1st edn. New York: Rowman \& Littlefield Publishers, 2017.

22 Chakraborty R, El-Jawahri AR, Litzow MR, Syrjala KL. A systemic review of religious beliefs about major end-of-life issues in the five major world religions. Palliat Support Care 2017;15:609-22.

23 Khalid I, Hamad W], Khalid TJ, Kadri M, Qushmaq I. End-of-life Care in Muslim brain-dead patients: a 10 year experience. Am J Hosp Palliat Med 2012;30:413-8. 
24 Leong M, Olnick S, Akmal T, Copenhave A, Rzzak R. How Islam influences end-of-life care: education for palliative care clinicians. J Pain Sympt Manag 2016;52:771-4.

25 Sachedina A. End-of-life: the Islamic view. Lancet 2005;366:774-9.

26 Sharif A. Organ Donations and Islam - Challenges and Opportunities. Transplantation 2012;94:442-6.

27 Centre for Islam and Medicine. Organ Donation in Islam. Available online http://thecim.org.uk/product/odbooklet/ [Accessed 10 October 2017].

28 Katme M. Muslim medical reasons against assisted suicide. In: Godlee F (eds). Assisted dying - time for a full and fair debate. BMJ 2015;351:h4517.

29 Narimisa M. Euthanasia in Islamic views. Eur Sci J 2014:2:170-3.

30 Al-Shahri MZ, Al-Khenaizan A. Palliative care for Muslim patients. J Support Oncol 2005;3:432-6.

31 Sarhill N, LeGrand S, Islambouli R, Davis MP, Walsh D. The terminally ill Muslim: death and dying from the Muslim perspective. Am J Hosp Palliat Care 2001;18:251-5.

32 Kinzbrunner BM. Jewish medical ethics and end-of-life care. J Palliat Med 2004;7:558-73.

33 Gabbay E, McCarthy MW, Fins J]. The care of the Ultra-Orthodox Jewish Patient. J Relig Health 2017:56:545-560.

34 Dorff EN. End-of-life: Jewish Perspectives. Lancet 2005;366:862-65.

35 Prosser R. Korman D, Feinstein A. An Orthodox Perspective of the Jewish End-of-life Experience. Home Health Nurse 2012;30:579585.

36 Thorns A, Sykes N. Opiod use in the last week of life and implications for end-of-life decision making. Lancet 2000;356:398-9.

37 Academy of Medical Royal Colleges. A code of practice for the diagnosis and confirmation of death. London, 2005. Available online at http://aomrc.org.uk/wp-content/uploads/2016/04/Code_ Practice_Confirmation_Diagnosis_Death_1008-4.pdf [Accessed 10 October 2017].

38 Rosner F. Jewish Perspectives on Death and Dying. J Halacha Contemporary Society 1986;11:50-69.

39 Harvard Medical School Ad Hoc Committee. A definition of irreversible coma report of the ad hoc committee of the Harvard Medical School to examine the definition of brain death. JAMA 1968:205:337-40.

40 Bauer-Wu S Barrett R, Yeager K. Spiritual Perspectives and practices at the end-of-life: A review of the major world religions and application to palliative care. Indian J Palliat Care 2007:13:53-8.
41 Deshpande O, Reid MC, Rao AS. Attitudes of Asian-Indian Hindus towards end-of-life care. J Am Geriatr Soc 2005;53:131-5.

42 Thrane S. Hindu end-of-life death, dying, suffering and Karma. J Hospice Palliat Nursing 2010;12:337-42.

43 Shanmugasundaram S, O'Connor M, Sellick K. Culturally competent care at the end-of-life - a Hindu perspective. End-of-life Care 2010;4:26-31.

44 Firth S. End-of-life: A Hindu view. Lancet 2005;366:682-6.

45 Sharma H, Jagdish V, Anusha P, Bharti S. End-of-life care: Indian Perspective. Indian J Psychiatry 2013;55:s293-8.

46 Lakhan SE. Hiduism: Life and Death. Student BMJ 2008;16:294336.

47 Ahluwalia M, Mohabir RK. Turning to Waheguru: religious and cultural coping mechanisms of bereaved Sikhs. J Death Dying 2017;0:1-12.

48 Ebrahim S, Bance S, Bowman KW. Sikh Perspectives towards Death and End-of-Life Care. J Palliat Care 2011;27:170-4.

49 Gatrad R, Panesar SS, Brown E, Notta H, Sheikh A. Palliative care for Sikhs. Int J Palliat Nursing 2001;9:496-8.

50 Sikh Sewak Chaplaincy. A Guide to Sikhism: Key Issues in Healthcare Practice. United Kingdom Sikh Healthcare Chaplaincy Group, 2011. Available online www.sikhchaplaincy.org.uk/images/ publications/a_guide_to_sikhism__key_issues_in_healthcare_ practice.pdf [Accessed 2 August 2017].

51 Singh H. Caring for a Sikh Patient. United Kingdom Sikh Healthcare Chaplaincy Group, 2009. Available online www.sikhchaplaincy.org. uk/images/publications/booklet-caring_for_a_sikh_patient.pdf [Accessed 2 August 2017].

52 Sikh Link and Sikh Interfaith Council of Victoria. Sikh Patients in Hospitals: A Guide For Healthcare Professionals. Victoria, Australia, 2002. Available online www.spiritualhealthvictoria.org.au/_ literature_193602/Sikh_Patients_in_Hospital [Accessed 2 August 2017].

Address for correspondence: Dr Mohsin I Choudry, Clinical Effectiveness and Evaluation Unit, 11 St Andrews Place, Regent's Park, London NW1 4LE, UK.

Email:mc08@doctors.org.uk 